\title{
The Effect of GeoGebra in Three-Dimensional Geometry Learning on Students' Mathematical Communication Ability
}

\author{
Yaya S. Kusumah \\ Prof., Universitas Pendidikan Indonesia, Bandung, Indonesia, \\ yayaskusumah@yahoo.com \\ Dedek Kustiawati \\ Universitas Islam Negeri Syarif Hidayatullah, Jakarta, Indonesia, \\ dedek.kustiawati.@uinjkt.ac.id

\section{Tatang Herman} \\ Prof., Universitas Pendidikan Indonesia, Bandung, Indonesia, tatangherman@upi.edu
}

The purpose of this research is to analyze the effect of GeoGebra in threedimensional geometry learning on students 'mathematical communication ability as a whole and based on students' prior mathematical abilities. This quasiexperimental research with randomized posttest only design included 84 XII grade students in high school in Central Jakarta, Indonesia. Before the research, students were grouped based on their prior mathematical abilities including high, medium and low groups. The research data were the results of mathematical communication skills tests consisting of 7 questions which were then analyzed by Mann- Whitney test. The results reveal that overall and for students with high and medium mathematical prior abilities, there were significant differences in mathematical communication skills between students who received GeoGebra assisted Geometry learning and students who obtained conventional mathematics learning, while for students with low prior mathematical ability, there is no significant difference.

Keywords: GeoGebra, three-dimensional geometry, mathematical communication ability, prior mathematical ability, quasi-experimental

\section{INTRODUCTION}

Mathematical communication ability is one of the important mathematical thinking abilities to improve. The National Council of Teachers of Mathematics (NCTM) and the Indonesian Ministry of Education and Culture set mathematical communication skills as one of the standard abilities students must possess in learning mathematics (NCTM, 2000) (Ministry of Education and Culture, 2016). Mathematical communication ability

Citation: Kusumah, Y. S., Kustiawati, D., \& Herman, T. (2020). The Effect of GeoGebra in ThreeDimensional Geometry Learning on Students' Mathematical Communication Ability. International Journal of Instruction, 13(2), 895-908. https://doi.org/10.29333/iji.2020.13260a 
is a way to share mathematical ideas and clarify understanding of a mathematical idea. (NCTM, 2000).

Mathematical communication ability helps students building conceptual understanding of a concept and providing opportunities for students to clarify their understanding and consolidate mathematical ideas (Hirschfeld-Coton, 2008). Mathematical communication has an important role in learning mathematics because through mathematical communication students can express, explain, describe, and listen to an understanding of mathematics (Paridjo, 2017). Communication ability is needed to understand mathematical ideas appropriately. Weak communication ability will weaken other mathematical abilities. Students who have high mathematical communication ability can make diverse representations and is easier to find alternative solutions to problem solving (Qohar, 2011).

One material that requires mathematical communication skills is geometry. Geometry is one of the essential materials in the Indonesian curriculum and taught to students from elementary school to the level of lectures (Jelatu et.al, 2018). Therefore, it is important to improve students' mathematical communication ability, especially in the field of geometry.

On the other hand, there is a fact that the mathematical communication ability of Indonesian students is still low. Mathematical communication ability included in levels 5 and 6 in the PISA assessment (PISA, 2015). The 2015 PISA results show that scores of Indonesian students for level 5 and 6 only range from $0-0.6 \%$ (PISA, 2015). More specifically in learning geometry in the classroom, there are many difficulties encountered by teachers and students because geometric learning involves more abstract concepts than concrete concepts (Tutkun\&Ozturk, 2013). Geometry learning which is presented textually by using pencils and paper and involves concepts that are not related to students' contexts causes students difficulties in understanding the various geometric concepts presented (Jelatu, 2017).

The low mathematical communication ability of students, especially in geometry material, is closely related to the learning process in class. The integration of technology in education, especially in mathematics learning, becomes an important matter and is becoming a trend (Azizul\& Din, 2016). One software that can be used in geometry learning is GeoGebra. Geometry learning using GeoGebra can help students to see abstract concepts, make connections, and discover mathematical concepts (Antohe, 2009). This study will analyze the effect of GeoGebra in learning three-dimensional geometry to ward students' mathematical communication ability as a whole and based on prior mathematical abilities.

\section{GeoGebra in Three-Dimensional Geometry Learning}

GeoGebra is software that is freely available for teaching and learning mathematics with features suitable for topics such as geometry and algebra (Azizul\& Din, 2016). GeoGebra is a dynamic software that addresses the concepts of Geometry, Algebra, and 
Calculus (Hohenwarter et.al, 2010). GeoGebra can be used to strengthen students' understanding of concepts that have been used and as a means to express or construct new concepts (Hohenwarter et.al, 2008). GeoGebra software is an interactive media that allows students to explore various mathematical concepts. The use of GeoGebra in learning can help teachers improve student understanding of mathematical concepts and procedures (Hutkemri \&Zakaria, 2012) (Zulnaidi, H., \&Zamri, 2017). GeoGebraf acilitates interactive assessment to help people involved in the learning process (Murni et.al, 2017).

The following is one example of using GeoGebra in learning three-dimensional geometry to determine the distance between point and fields:

"Suppose $\mathrm{ABCDEFGH}$ is a cube with $\mathrm{AB}=5$. We will find a distance point $\mathrm{F}$ to the ACH field."

The steps to determine the distance of point $\mathrm{F}$ to $\mathrm{ACH}$ fields using GeoGebra are as follows:

1. Create an ABCDEFGH cube on Geogebra.

2. To create an ACH field, select "Polygon" then click points A, C, H, A respectively.

3. Draw a line through $\mathrm{F}$ and perpendicular to the ACH field by clicking "Perpendicular Line", click "poly1" then also click "F".

4. To mark the intersection, select "Intersect" then click line "b" and click "poly1" so that the "I" point is obtained.

5. To calculate the distance, just click "Distance or length" then click "I" and "F", then JF distance will appear.

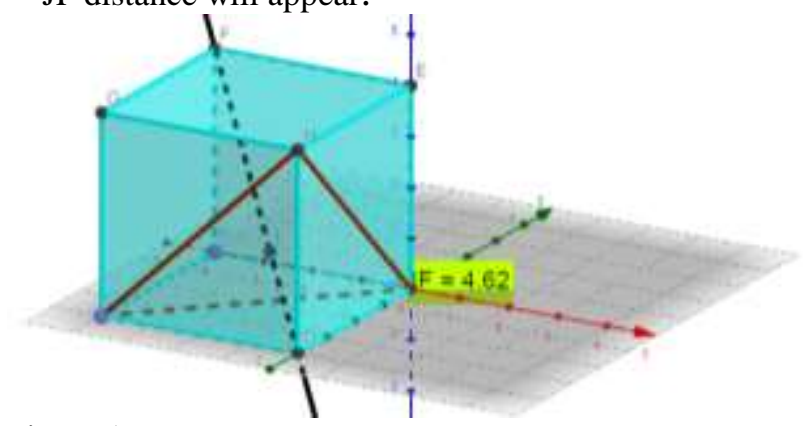

Figure 1

Mathematical Communication Ability

Communication ability includes activities such as active listening, asking questions and answering questions, giving explanations, and effective debate techniques (NCTM, 2000). Communication is the process of expressing mathematical ideas and understanding verbally, visually, and in writing, using numbers, symbols, images, 
graphics, diagrams, and words. Students communicate for various purposes and different audiences, such as teachers, colleagues, groups of students, or the whole class. Communication is the delivery of meaning through various forms of oral, written, and visual, for example giving explanations of reasoning or justification of results verbally or in writing and communicating mathematical ideas and solutions in writing, using numbers and algebraic symbols, and visually, using images, diagrams, charts, tables, graphs and concrete objects. Through communication, students can reflect on and clarify their ideas, their understanding of the relationship of mathematics, and their mathematical arguments (Ministry of Education Ontario, 2005). Communication through mathematical ideas can be utilized in various perspectives, the way students think can be honed, understand growth can be measured; student thinking can be consolidated and organized; mathematical knowledge and development of student problems can be improved; and mathematical communication can be done (Hidayati, 2016). Mathematical communication ability can be built by observing explaining concepts, differentiating a mathematical concept, proposing theories, describing problems by manipulating images or graphics and explaining the results of one's own thinking. (Whitin, 2002). Communication ability is one of the factors that contribute to determining student success in solving problems (Stacey, 2005). According to Zulnaidi, communication is a process that includes interaction and perception. Communication is the exchange of specific information where there is a process of sending verbal messages such as words and nonverbal such as symbols, gestures, etc. Communication always has certain situational characters determined by the relationship between participants (Anatolievna, 2017). Communication is an important part of mathematics and mathematics education. Mathematical learning will be more developed when interactions between students and between teachers and students are established on the basis of good communication skills (Wilkins \&Kosko, 2006) Lopatto divides communication skills into 3 types including skills on oral communication, skill at written communication, and skill at visual communication (Lopatto, 2003).

In this study three indicators of mathematical communication ability are used, namely written text, drawing, mathematical expression (Ansari, 2003). The following are presented sub-indicators of each aspect: 
Table 1

Indicators of MathematicalCommunication Ability

The Aspect of

Mathematical

Communication Ability

Written Text

Drawing

Mathematical

Expressions
Indicators of Mathematical Communication Ability

Give answers using their own language, make models using or writing using writing and algebra, explain and make questions about mathematics that have been studied, discussed, and written about mathematics, compiling arguments and generalizations.

Reflecting real objects, images, and diagrams into mathematical ideas and vice versa

Express mathematical concepts by expressing daily events in mathematical language or symbols.

\section{METHOD}

\section{Method and Design}

This research uses a quantitative approach with a quasi-experimental method. The quasiexperimental method is used because there are other variables in the study that are difficult to control. This study involved the experimental group, which is the group given the treatment of learning using GeoGebra and the control group, which is the group given the conventional learning model treatment. The design of this study is Randomized Control Group Post Test Only Researcher wants to analyze the mathematical communication skills of students given learning with GeoGebra and students are given conventional learning. Before the study, students in the experimental and control groups were first grouped based on their prior abilities, namely low, medium, or high. The dependent variable of this study is students' mathematical communication ability while the independent variable is learning using GeoGebra. The research design is illustrated in the following table:

Table 2

Research Design

\begin{tabular}{ccc}
\hline Class & Treatment & Post Test \\
\hline $\mathrm{E}$ & $\mathrm{X}$ & $\mathrm{O}$ \\
$\mathrm{K}$ & - & $\mathrm{O}$ \\
\hline
\end{tabular}

\section{Information:}

E: Experimental Class

$\mathrm{K}$ : Control Class

$\mathrm{X}$ : Application of learning with the Concrete-PictorialAbstract (C-P-A) learning model with a knowledge classification strategy

O: Post Test Results 


\section{Participant}

The population in this study were grade XII students of State High Schools in Central Jakarta, Indonesia in the academic year 2017/2018. Furthermore, the sample from this study was taken from a population of two classes selected by the Cluster Random Sampling technique. Each was randomly selected to be assigned to the experimental class (the class has given learning with GeoGebra) and the control class (the class has given the conventional learning model). The experimental class consisted of 41 students, 8 students in the high MPK category, 25 students in the moderate MPK category and 8 low MPK categories. The control class consisted of 41 students, 8 students in the high MPK category, 26 students in the moderate MPK category and 7 students in the low MPK category. This situation can be shown in the following table:

Table 3

Number of Students by MPK

\begin{tabular}{llll}
\hline & & Class & \\
\hline & & Experiment & Control \\
\hline Hiior & High & 8 & 8 \\
$\begin{array}{l}\text { Mathematical } \\
\text { Ability }\end{array}$ & Moderate & 25 & 26 \\
& Low & 8 & 7 \\
\hline
\end{tabular}

\section{Data Collection}

The data in this study were obtained from the results of the student's mathematical communication ability test from experiment and control class on the three-dimensional material given after the learning was completed. The mathematical communication ability test instrument used in this study measures three aspects namely written text, drawing, and mathematical expression.

\section{Data Analysis}

The data analysis used in this study is descriptive and inferential statistical analysis. Hypothesis testing is done through t-test and Mann- Whitney test with a significance level of 0.05 where previously normality tests were also carried out with KolmogorovSmirnov and homogeneity tests with Levene's test.

\section{FINDINGS}

\section{Data on Student Mathematical Communication Ability as a Whole}

The results of the descriptive statistics for achieving students' mathematical communication skills as a whole are as follows: 
Table 4

Descriptive Statistics of Students' Mathematical Communication Ability Score as a Whole

\begin{tabular}{|c|c|c|c|c|c|c|c|c|c|c|}
\hline & \multicolumn{5}{|c|}{ Experiment Class } & \multicolumn{5}{|c|}{ Control Class } \\
\hline Ideal & $\mathrm{N}$ & & & & & $\mathrm{N}$ & & & & \\
\hline Score & & $x_{\min }$ & $x_{\text {maks }}$ & $\bar{x}$ & $s_{\text {d }}$ & & $x_{\min }$ & $x_{\text {maks }}$ & $\bar{x}$ & $S_{d}$ \\
\hline 24 & 41 & 14 & 22 & 18.46 & 2.31 & 41 & 8 & 22 & 15.85 & 4.02 \\
\hline
\end{tabular}

Students who get GeoGebra learning is better than students who get conventional learning. Tables $5 \mathrm{a}, 5 \mathrm{~b}$ and $5 \mathrm{c}$ show the results of the normality test. Homogeneity test, T-Test and Mann Whitney test with a significant 0.05 .

Table 5a

Data Normality Test of Student's Mathematical Communication Ability as a Whole

\begin{tabular}{llll}
\hline Class & \multicolumn{2}{l}{ Shapiro-Wilk } & Interprestasi \\
\cline { 2 - 3 } & Df & Sig. & \\
\hline Experiment & 41 & 0.78 & Normal Distribution \\
Control & 41 & 0.23 & Not Normal Distribution \\
\hline
\end{tabular}

Table 5a shows that the test score data of students' mathematical communication ability for the experimental class are normally distributed and the control class is not normally distributed.

Table $5 b$

Test Data Homogeneity of Students' Mathematical Communication Ability as a Whole

\begin{tabular}{ll}
\hline Statistic Levene & Sig. \\
\hline 2.83 & 0.97 \\
\hline
\end{tabular}

It Table 5b, note that the value of sig. $>0.05$ that means hypothesis Ho is accepted and $\mathrm{H} 1$ is rejected. This means that the data from the experimental and control class as a whole are homogeneous. Furthermore, to find out whether there were differences between the classes that were significantly different, a non-parametric test was performed with the Mann-Whitney test. With the hypothesis: there is no significant difference in the improvement of communication ability between students given Geogebra assisted geometry learning and students who learn mathematics can be seen from the PMK group. To test the hypothesis, the statistical hypothesis is formulated as follows:

Table 5c

Test the Difference of Student's Mathematical Communication Ability as a Whole

\begin{tabular}{ll}
\hline Asymp. Sig. (2-tailed) & Interpretation \\
\hline 0.04 & Ho rejected \\
\hline
\end{tabular}

Based on Table 5c, the value of Sig. $<0.05$, so reject Ho. This means that there are significant differences in the improvement of mathematical communication skills 
between students who get Geogebra assisted Geometry learning and students who get conventional mathematics learning.

\section{Student Mathematical Communication Ability Data Based on Prior Mathematical Abilities}

The results of descriptive statistics for achieving mathematical communication skills of students based on the KAM category are as follows:

Table 6

Descriptive Statistics Mathematical Communication Ability Based on Prior Mathematical Ability

\begin{tabular}{|c|c|c|c|c|c|c|c|c|c|c|c|}
\hline \multirow{2}{*}{$\begin{array}{l}\text { Prior } \\
\text { Mathemat } \\
\text { ical } \\
\text { Abilities }\end{array}$} & \multirow{2}{*}{$\begin{array}{l}\text { Ideal } \\
\text { Score }\end{array}$} & \multicolumn{5}{|c|}{ Experiment Class } & \multicolumn{5}{|c|}{ Control Class } \\
\hline & & $\mathrm{N}$ & $x_{\min }$ & $x_{\text {maks }}$ & $\bar{x}$ & $S_{d}$ & $\mathrm{~N}$ & $x_{\min }$ & $x_{\text {maks }}$ & $\bar{x}$ & $S_{d}$ \\
\hline High & 24 & 9 & 0.43 & 0.78 & 0.61 & 0.13 & 8 & 0.13 & 0.78 & 0.59 & 0.27 \\
\hline Moderate & & 24 & 0.00 & 0.75 & 0.50 & 0.17 & 26 & 0.00 & 0.71 & 0.36 & 0.14 \\
\hline Low & & 8 & 0.27 & 0.77 & 0.48 & 0.17 & 7 & 0.12 & 0.45 & 0.28 & 0.12 \\
\hline
\end{tabular}

Students who get GeoGebra learning is better than students who get conventional learning. The results of the achievement of students' mathematical communication ability based on high prior mathematical ability, moderate prior mathematical ability, and low prior mathematical ability must meet the difference test requirements between students who receive learning with GeoGebra and students who receive regular learning. Tables $7 \mathrm{a}, 7 \mathrm{~b}$, and $7 \mathrm{c}$ show the results of the normality test. Homogeneity test, and Mann Whitney test with a significant 0.05 .

Table 7a

Data Normality Test of Student Mathematical Communication Ability Based on Prior Mathematical Abilities

\begin{tabular}{lllllll}
\hline Category & & Class & $\mathrm{N}$ & $\begin{array}{l}\text { Sig. (2- } \\
\text { tailed) }\end{array}$ & Ho & Interpretation \\
& High & Experiment & 9 & 0.42 & Accepted & Normal \\
PRIOR & & Control & 8 & 0.63 & Accepted & Normal \\
\cline { 2 - 6 } MATHEMATI & Moderate & Experiment & 24 & 0.02 & Rejected & Not Normal \\
CAL & & Control & 26 & 0.89 & Accepted & Normal \\
\cline { 2 - 6 } ABILITY & Low & Experiment & 8 & 0.25 & Accepted & Normal \\
& & Control & 7 & 0.95 & Accepted & Normal \\
\hline
\end{tabular}

Table 7a shows that the score data tests students' mathematical communication ability for the experimental and control classes as general except the group with moderate prior ability in the experimental class has a sig value. $>0.05$. Thus, $\mathrm{H}_{0}$ is accepted and rejected $\mathrm{H} 1$, meaning that data is normally distributed while the group with moderate prior ability in the experimental class has a sig value. $<0.05$ so that it is not normally distributed. 
Table $7 \mathrm{~b}$

Test the Homogeneity of Students' Mathematical Communication Ability Based on Prior Mathematical Abilities

\begin{tabular}{llll}
\hline Prior Mathematical Abilities & Asymp. Sig. & Ho & Interpretation \\
\hline High & 0.04 & Rejected & Not Homogeny \\
Moderate & 0.01 & Rejected & Not Homogeny \\
Low & 0.06 & Rejected & Not Homogeny \\
\hline
\end{tabular}

In Table $7 \mathrm{~b}$ it is known that the sig value. $<0.05$ so the hypothesis $\mathrm{H} 0$ is rejected and $\mathrm{H} 1$ is accepted. This means that there are no homogeneous data from the three groups. Furthermore, to find out whether the differences in the increase in learning outcomes between the experimental class and the control class differed significantly, nonparametric tests were performed with Mann-Whitney test. With the hypothesis: there is no significant difference in the improvement of mathematical communication ability between students who get GeoGebra assisted Geometry learning and students who get conventional mathematics learning in terms of the prior mathematical abilities group. The t-test and Mann-Whitney test results are presented in the table as follows:

Table 7c

Test of Difference in Increased Mathematical Communication Ability Based on Prior Mathematical Abilities

\begin{tabular}{lll}
\hline Prior Mathematical Abilities & Asymp. Sig. & Interpretation \\
\hline High & 0.04 & Ho rejected \\
Moderate & 0.01 & Ho rejected \\
Low & 0.06 & Ho rejected \\
\hline
\end{tabular}

Based on table 7c, it can be concluded that mathematical communication skills based on prior mathematical abilities are obtained, namely:

1. At low prior mathematical abilities levels, there is no significant difference in mathematical communication skills between students who get Geogebra-assisted Geometry learning and students who get conventional mathematics learning in terms of high, medium and low groups

2. At the high and medium level of prior mathematical abilities, there are differences in mathematical communication skills of students who get learning Geogebra assisted geometry is better than students who get conventional mathematics learning in terms of high, medium and low groups.

\section{DISCUSSION}

The findings of this study reveals that students' mathematical communication ability in three- dimensional geometry who given by GeoGebra were higher than students taught with conventional learning. This finding is in line with the results of a study conducted by Jelatu et al. (2018) where it was found that learning with the REACT strategy assisted by GeoGebra supports the achievement of higher understanding of geometric concepts compared to conventional learning. The findings of this study are also in line 
with the research of Saha et al (2010) which revealed that the use of GeoGebra improved student performance in learning Geometry coordinates. Research conducted by Akcakin (2018) also revealed that the use of GeoGebra as a dynamic mathematical device can increase student motivation in achieving goals.

The use of GeoGebra in improving mathematical communication skills is closely related to the functions in GeoGebra which can visualize the concept of abstraction geometry so that it can be more interesting and easily understood by students. Revealed that learning with computer media is more effective than conventional learning because it makes students faster in learning a concept compared to conventional learning. (Kusumah, 2010). The research findings of reveal that GeoGebra influences the solution discovery method (Farihah, 2018). GeoGebra supports students discovering new ways of thinking, manipulating, and analyzing mathematical modeling (Jarvis et.al, 2011). GeoGebra supports learning with multiple representations, computations, documentation, and webfriendly features that expand the range of learning (Bu et.al, 2011).

Pedagogical competence is seen as the ability of teachers to manage to learn, the design of teacher learning activities is expected to pay attention to the material, strategy, technology or surrounding culture in helping to realize active, creative, fun and meaningful learning. This software can be used both as a teaching tool to explore and discover mathematical properties and as a tool for the interactive creation of teaching material (Richardson, S., 2009)

The following is presented the differences in answers using GeoGebra with answers in the conventional class in the 3-dimensional mathematical communication problem:

Question:

"Given a cube ABCD. EFGH with a length of $A B$ is $6 \mathrm{~cm}$. Paint it and calculate the distance between Point $\mathrm{E}$ and the ADGF field! "

Answers using GeoGebra:

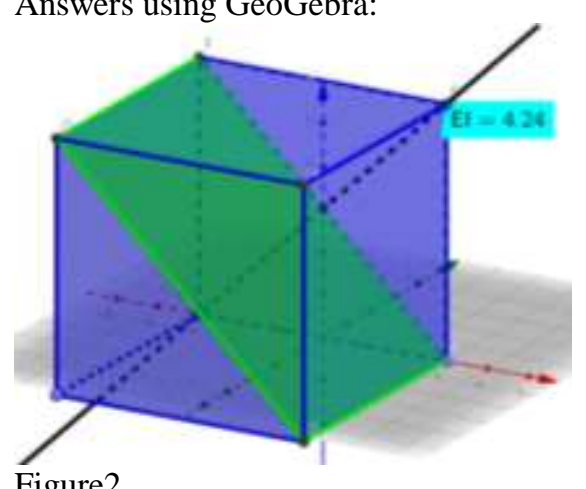

Figure2

The answer in conventional class XII 


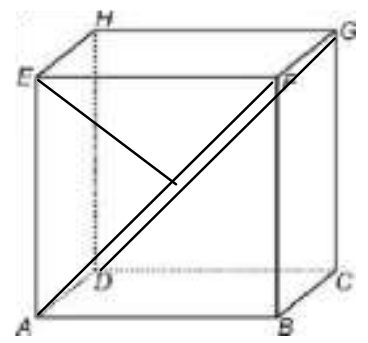

Figure 3

Distance $\mathrm{E}$ with the ADGF field = half of the diagonal space, then the distance $\mathrm{E}$ to

$$
\text { ADGF field }=\frac{1}{2} 6 \sqrt{3}=3 \sqrt{3}
$$

Based on the answers above, it can be seen that the use of GeoGebra can display cube images, fields in cubes, and the distance between E points and ADFG fields more clearly than not using GeoGebra. By using GeoGebra, the distance between points and fields can be clearly seen by students so that they can support the improvement of students' mathematical communication ability.

This study also reveals that learning with GeoGebra was significant for students with high and moderate mathematical prior abilities and did not produce significant differences in groups of students with low prior mathematical abilities. This finding means that the use of GeoGebra is relatively suitable for students with high and medium mathematical initial ability groups and tends to be less suitable for students with a low mathematical initial ability group. Based on the results of this study, it can be said that the use of GeoGebra can improve mathematical communication skills if students have sufficient prior abilities.

\section{CONCLUSION AND SUGGESTION}

Based on the results of this research, it can be concluded that students' mathematical communication ability will be increased if taught with GeoGebra compared to conventional learning. In addition, it can be concluded also that the use of GeoGebra is significant for students' mathematical communication ability as a whole, students with high and medium mathematical prior abilities and not significant for students with low prior mathematical abilities.

Because in general, the use of GeoGebra can improve students' mathematical communication skills, it is recommended for mathematics teachers to use GeoGebra in Geometry learning, especially in a three-dimensional material. 


\section{REFERENCES}

Akçakın, V (2018). Teaching mathematical functions using geometric functions approach and its effect on ninth grade students' motivation. International Journal of Instruction, 11(1), 17-32.

Anatolievna, S. T., Munirovna, N. A., Kasimovna, V. D., Mirzayanova, S. L., \& Anatolievna, B. T. (2017). Pedagogical management of university students' communication ability development. International Journal of Instruction, 10(3), 79-92.

Ansari, B. L. (2003). Developing mathematical reasoning and communication skills of high school students through think talk write strategy (Unpublished doctoral dissertation). FMIPA UPI Bandung.

Antohe, V. (2009). Limits of educational soft "GeoGebra" in a critical constructive review. Anale.Seria Informatică, VII(1), 47-54.

Azizul, S. M. J., \& Din, R. (2016). Teaching and learning geometry using GeoGebra software via MOOC. Journal of Personalized Learning, 2(1), 39-50.

Bu, L., Spector, J. M., \& Hacimeroglu, E. S. (2011). Toward model-centered mathematics learning and instruction using GeoGebra: A theoretical framework for learning mathematics. In L. Bu, \& R. Schoen (Eds.), Model-centered learning: Pathways to mathematical understanding using GeoGebra (pp.13-40).nRotterdam: Sense Publisher

Farihah, U. (2018) Student's thinking preferences in solving mathematics problems based on learning styles: A comparison of paper-pencil and GeoGebra. Journal of Physics: Conf. Series, 8-9.

Hidayati, W. S. (2016). Description Verbal mathematics communication of students prospective mathematics teacher in teaching practice. IOSR Journal of Research \& Method in Education (IOSR-JRME), 6, 8-11.

Hirschfeld-Coton, K. (2008). Mathematical communication, conceptual understanding, and students' atitudes toward mathematics. Action Research Projects. 4.

Hohenwarter, M., Hohenwarter, J., Kreis, Y., \& Lavicza, Z. (2010). Teaching and calculus with free dynamic mathematics software GeoGebra. Paper presented at the $11^{\text {th }}$ Internatonal Congress on Mathematical Education, Mexico.

Hutkemri \& Zakaria, E. (2012). The effect of GeoGebra on students 'conceptual and procedural knowledge of function. Indian Journal of Science and Technology, 5(12), $10-110$.

Kusumah, Y. S. (2010) Study of the application of computer-based mathematics learning models to type of interaction tutorials in increasing students' critical and 
creative thinking abilities. Papers in the 2004 Mathematics National Seminar. Bandung: FPMIPA-UPI Mathematics Education Department.

Jarvis, D., Hohenwarteri M., \& Lavicza, Z. (2011). GeoGebra, democratic access, and sustainability: Realizing the 21 st-century potential of dynamic mathematics for all. In L. $\mathrm{Bu}, \&$ R. Schoen (Eds.), Model-centered learning: Pathways to mathematical understanding using GeoGebra (pp.231-241). Rotterdam: Sense Publisher.

Jelatu, S., Sariyasa, \& Ardana, I. M. (2018). Effect of GeoGebra-aided REACT strategy on understanding of geometry concepts. International Journal of Instruction, 11(4), 325-336.

Ministry of Education Indonesia. (2016). Regulation of the minister of education and culture no. 21 of 2016 concerning standard content. Retrieved www.bsnpindonesia.org.

Ministry of Education Ontario. (2005). The Ontarion Curriculum Grades 1-8 Mathematics.

Murni, V., Sariyasa, S., Ardana, I. M. (2017). GeoGebra assists discovery learning model for problem solving ability and attitude toward mathematics. J. of Phys: Conf. Series, 895, 1-6.

NCTM. (2000). Principles and standards for school mathematics. Reston: NCTM.

OECD. (2016). PISA 2015 results: Excellence and equity in education volume 1. Paris: OECD Publishing.

Paridjo, \& St. Budi, W. (2017). Analysis mathematical communication skills students in the matter algebra based NCTM. OSR Journal of Mathematics. 13.

Qohar, A. (2011). Mathematical communication: What and how to develop it in mathematics learning? Proceeding at International Seminar and the Fourth National Conference on Mathematics Education.

Richardson, S. (2009). Mathematics teachers' development, exploration, and advancement of technological pedagogical content knowledge in the teaching and learning of algebra. Contemporary Issues in Technology and Teacher Education, 9(2), 117-130.

Saha, R. A., Ayub, A. F. M., \& Tarmizi, R. A. (2010). The effects of GeoGebra on mathematics achievement: Enlightening coordinate geometry learning. Procedia-Social and Behavioral Sciences, 8, 686-693.

Sariyasa. (2017). Creating dynamic learning environment to enhance students' engagement in learning geometry. Journal of Physics: Conf. Series, 824(1), 1-5.

Stacey, K. (2005). The place of problem solving in contemporary mathematics curriculum document. Journal of Mathematical Behaviour, 24, 341-350. 
Tutkun, O. F., \& Sulaiman, H. (2013). The effect of GeoGebra mathematical software to academic success and the level of van Hiele geometrical thinking. International Journal of Academic Research, 5(4), 22-28.

Whitin, P., \& Whitin, D. J. (2002). Promoting communication in the mathematics classroom. Teaching Children Mathematics, 9(4), 205-211.

Wilkins, \& Kosko. (2006). Mathematical communication and its relation to the frequency of manipulative use. International Journal of Mathematics Education,5(2), 79-90.

Zulnaidi, H., \& Zamri, S. N. A. S. (2017). The effectiveness of the GeoGebra software: The intermediary role of procedural knowledge on students' conceptual knowledge and their achievement in mathematics. Eurasia Journal of Mathematics, Science and Technology Education, 13(6), 2155-2180. 